\title{
Men with testosterone deficiency and a history of cardiovascular diseases benefit from long-term testosterone therapy: observational, real-life data from a registry study
}

This article was published in the following Dove Press journal:

Vascular Health and Risk Management

14 June 2016

Number of times this article has been viewed

\author{
Ahmad Haider' \\ Aksam Yassin 2-4 \\ Karim Sultan Haider ${ }^{1}$ \\ Gheorghe Doros ${ }^{5}$ \\ Farid Saad ${ }^{4,6}$ \\ Giuseppe MC Rosano 7 \\ 'Private Urology Practice, \\ Bremerhaven, ${ }^{2}$ Institute for Urology \\ and Andrology, Segeberger Kliniken, \\ Norderstedt, ${ }^{3}$ Department of \\ Preventive Medicine, Men's Health \\ Program, Dresden International \\ University, Dresden, Germany; \\ ${ }^{4}$ Department of Urology, Gulf \\ Medical University, Ajman, United \\ Arab Emirates; ${ }^{5}$ Department for \\ Epidemiology and Statistics, Boston \\ University School of Public Health, \\ Boston, MA, USA; ${ }^{6}$ Global Medical \\ Affairs Andrology, Bayer Pharma AG, \\ Berlin, Germany; ${ }^{7}$ Department of \\ Cardiology, Centre for Clinical and \\ Basic Science, San Raffaele-Roma, \\ Rome, Italy
}

Background/objectives: Long-term testosterone therapy (TTh) in men with hypogonadism has been shown to improve all components of the metabolic syndrome. In this study, we investigated the effects of long-term TTh up to 8 years in hypogonadal men with a history of cardiovascular disease (CVD).

Patients and methods: In two urological clinics observational registries, we identified 77 hypogonadal men receiving TTh who also had a history of CVD. The effects of TTh on anthropometric and metabolic parameters were investigated for a maximum duration of 8 years. Any occurrence of major adverse cardiovascular events was reported. All men received long-acting injections of testosterone undecanoate at 3-monthly intervals.

Results: In 77 hypogonadal men with a history of CVD who received TTh, we observed a significant weight loss and a decrease in waist circumference and body mass index. Mean weight decreased from $114 \pm 13 \mathrm{~kg}$ to $91 \pm 9 \mathrm{~kg}$, change from baseline: $-24 \pm 1 \mathrm{~kg}$ and $-20.2 \% \pm 0.5 \%$. Waist circumference decreased from $112 \pm 8 \mathrm{~cm}$ to $99 \pm 6 \mathrm{~cm}$, change from baseline: $-13 \pm 0.3 \mathrm{~cm}$. Body mass index decreased from $37 \pm 4$ to $29 \pm 3$, change from baseline: $-8 \pm 0.2 \mathrm{~kg} / \mathrm{m}^{2}$. Cardiometabolic parameters such as lipid pattern, glycemic control, blood pressure, heart rate, and pulse pressure all improved significantly and sustainably. No patient suffered a major adverse cardiovascular event during the full observation time.

Conclusion: In men with hypogonadism, TTh appears to be effective in achieving sustained improvements in all cardiometabolic risk factors and may be effective as an add-on measure in the secondary prevention of cardiovascular events in hypogonadal men with a history of CVD. Keywords: testosterone, long-term testosterone therapy, cardiovascular risk, hypogonadism, secondary prevention

\section{Introduction}

Testosterone (T) deficiency (TD; hypogonadism) is a well-established medical condition, which has been recognized for $>70$ years. T therapy (TTh) has been long reported as an effective and safe treatment in patients with TD, and several studies have reported beneficial effects of TTh in patients with peripheral vascular disease and angina pectoris. ${ }^{1}$ Over the past several decades, a wealth of knowledge has accumulated regarding the negative impact of hypogonadism on men's overall health and quality of life. ${ }^{2}$ Furthermore, the deleterious effects of androgen deprivation therapy (ADT) in men with prostate cancer on cardiometabolic risk seem to be well established. ${ }^{3}$
Correspondence: Farid Saad Global Medical Affairs Andrology, Bayer Pharma AG, Muellerstr. 178, 13353 Berlin, Germany

Email farid.saad@bayer.com 
Despite the common belief that $\mathrm{T}$ may increase the incidence of coronary artery disease (CAD), the scientific evidence suggests that TD increases the likelihood and the degree of coronary atherosclerosis. ${ }^{4}$ Hypogonadism is associated with increased cardiometabolic risk and increased risk of all-cause and cardiovascular (CV) mortality, ${ }^{1,4-7}$ while higher $\mathrm{T}$ levels were associated with lower incidence of sudden cardiac arrest. ${ }^{8}$

Despite the wealth of knowledge in the field of TTh and $\mathrm{CV}$ health, ${ }^{1}$ a few studies have recently reported controversial outcomes. ${ }^{9-12}$ However, in response to a petition to place a black box warning on T products, both the US Food and Drug Administration and the European Medicines Agency have evaluated the available evidence and concluded that there was no credible evidence that TTh contributes to increased cardiovascular disease (CVD) risk. More recent medium-term studies have refuted such claims. ${ }^{13-19}$ To date, no long-term studies have assessed the effects of TTh in men with a history of CVD. Here, we report on the effects of long-term TTh in 77 men with TD and a history of CVD.

\section{Patients and methods}

\section{Patients}

From two prospective, cumulative observational registries of 622 unselected patients presenting to two urology clinics with hypogonadism (defined as $\mathrm{T} \leq 12.1 \mathrm{nmol} / \mathrm{L}$ in the presence of symptoms), we identified 77 men (12.4\% of all patients) with a history of CVD. In this subgroup, 77 men with a previous diagnosis of $\mathrm{CAD}(\mathrm{n}=48)$ and/or a history of myocardial infarction (MI; $n=40)$ and/or stroke $(n=7)$ were analyzed. Mean age at baseline was $61 \pm 5$ years and mean follow-up time $7.3 \pm 1.2$ years (minimum: 4 years and maximum: 8 years). All 77 men were continuously treated with testosterone undecanoate (TU) injections (Nebido ${ }^{\circledR}$; Bayer AG, Leverkusen, Germany) in 3-monthly intervals, following an initial interval of 6 weeks, for up to 8 years. Men were entered into the registry once they had received 1 year of treatment. Inclusion criteria were two separate morning measures of total testosterone $\leq 12.1 \mathrm{nmol} / \mathrm{L}$ and the presence of hypogonadal symptoms measured by the Aging Males' Symptoms scale (AMS). Exclusion criteria for $\mathrm{T}$ administration included previous treatment with androgens, prostate cancer, or any suspicion thereof, such as prostate-specific antigen levels $>4 \mathrm{ng} / \mathrm{mL}$ or abnormal findings upon digital rectal examination, International Prostate Symptom Score (IPSS) $>19$ points, breast cancer, recent angina, or severe untreated sleep apnea.

\section{Assessment and follow-up}

At each or each other visit, we measured the following parameters: total plasma T levels, weight, waist circumference (WC), body mass index (BMI), hemoglobin, hematocrit, fasting glucose levels, glycated hemoglobin $\left(\mathrm{HbA}_{1 \mathrm{c}}\right)$, systolic blood pressure (SBP), diastolic blood pressure (DPB), heart rate, pulse pressure, lipid profile (total cholesterol [TC], low-density lipoprotein [LDL] cholesterol, high-density lipoprotein [HDL] cholesterol, triglycerides [TGs]), C-reactive protein, and liver transaminases. We also assessed prostate volume, prostate-specific antigen, and questionnaires IPSS, AMS, and International Index of Erectile Function, Erectile Function domain (IIEF-EF). Measures were taken between two and four times per year, and annual average was calculated. Ethical guidelines as formulated by the German "Ärztekammer" (the German Medical Association) for observational studies in patients receiving standard treatment were followed. According to these guidelines, no formal ethical approval is required for the evaluation of results obtained during standard treatment. After receiving an explanation regarding the nature and the purpose of the study, all subjects provided written consent to be included in the registry and have their data analyzed. Measurements of the parameters measured in this study were carried out as previously described. ${ }^{20,21}$

Statistical analyses were described previously. Briefly, for continuous variables, mean, median, standard deviation, range, minimum, maximum, and sample size for the sample were reported at each time point. For categorical variables, the frequency distribution was reported. We tested the hypotheses regarding change in outcome scores across the study period by fitting a linear mixed-effects model to the data. Time (to indicate follow-up interviews) was included as a fixed effect in the model. A random effect was included in the model for the intercept. Estimation and test of change in scores were determined by computing the differences in least square means at baseline versus the score at each follow-up visit. ${ }^{20,21}$

\section{Results \\ Baseline characteristics}

Baseline clinical characteristics of the 77 patients included in the long-term registry are described in Table 1: mean age was $61 \pm 5$ years (minimum: 43 and maximum: 68). Approximately $52 \%$ of the subjects had a previous MI, and $9 \%$ had a previous stroke. A previous diagnosis of CAD had been made in $62 \%$ of the subjects. In all, $53 \%$ had type 2 diabetes mellitus. Furthermore, $94 \%$ of the subjects were on antihypertensives, $75 \%$ on statins, and $48 \%$ on antidiabetic medications.

\section{Effects of long-term TTh on weight loss, WC, and BMI}

A marked and significant weight loss (WL) was observed after 8 years of continuous TTh in the 77 hypogonadal men receiving 
Table I Baseline comorbidities and concomitant medication in 77 hypogonadal men with a history of cardiovascular diseases

\begin{tabular}{ll}
\hline Age (minimum; maximum) (years) & $60.65 \pm 4.98(43 ; 68)$ \\
Metabolic diseases & $71(92.2 \%)$ \\
Obesity & $5(6.5 \%)$ \\
Overweight & $41(53.2 \%)$ \\
Diabetes mellitus type 2 & $5(6.5 \%)$ \\
Diabetes mellitus type I & \\
Cardiovascular diseases & $40(51.9 \%)$ \\
History of myocardial infarction & $7(9.1 \%)$ \\
History of stroke & $48(62.3 \%)$ \\
Previous diagnosis of coronary artery disease & $77(100 \%)$ \\
Total cardiovascular diseases & \\
Medication use & $72(93.5 \%)$ \\
Antihypertensives & $58(75.3 \%)$ \\
Lipid-lowering medications & $37(48.1 \%)$ \\
Antidiabetic medications &
\end{tabular}

TTh (Figure 1A). WL was progressive and significant from year to year and amounted to $24 \mathrm{~kg}$ after 8 years. The percentage of change in weight over the follow-up period is shown in Figure 1B. Gradual and significant fractional change in weight is noted. The percentage of change was progressive and increased with continuous treatment and appeared more marked after the initial period (model adjusted $2.6 \%$ after 1 year, $7.1 \%$ after 2 years, $10.4 \%$ after 3 years, $13.2 \%$ after 4 years, $15.4 \%$ after 5 years, $17.4 \%$ after 6 years, $19.0 \%$ after 7 years, and $20.2 \%$ after 8 years). The gradual WL was accompanied by a marked and significant gradual decrease in WC (Figure 1C). The reduction in WC in response to TTh was significant from year to year and amounted to $13 \mathrm{~cm}$ at the end of the follow-up period of 8 years (model adjusted $1.7 \%$ after 1 year, $4.4 \%$ after 2 years, $6.3 \%$ after 3 years, $7.7 \%$ after 4 years, $8.8 \%$ after 5 years, $9.6 \%$ after 6 years, $10.4 \%$ after 7 years, and $11.1 \%$ after 8 years). The anthropometric data were also analyzed to determine the changes in BMI. As shown in Figure 1D, considerable and significant reduction in BMI was observed over the entire follow-up period with a mean reduction of $8 \mathrm{~kg} / \mathrm{m}^{2}$.

\section{Effects of long-term TTh on metabolic parameters}

Effects on $\mathrm{HbA}_{\mathrm{Ic}}$

Over the course of treatment, a significant and sustained change in the levels of $\mathrm{HbA}_{1 \mathrm{c}}$ occurred: $7.6 \%$ at baseline, $7.2 \%$ after 1 year, $6.8 \%$ after 2 years, $6.6 \%$ after 3 years, $6.4 \%$ after 4 years, $6.2 \%$ after 5 years, $6.0 \%$ after 6 years, $5.9 \%$ after 7 years, and $5.7 \%$ after 8 years (Figure 2). By the end of follow-up period, a reduction in $\mathrm{HbA}_{1 \mathrm{c}}$ of $2.0 \%$ was recorded $(P<0.0001)$.

Long-term TTh resulted in decreased fasting glucose from $6.0 \pm 1.2 \mathrm{mmol} / \mathrm{L}$ to $5.2 \pm 0.4 \mathrm{mmol} / \mathrm{L}$. The change from baseline was $-0.9 \pm 0.1 \mathrm{mmol} / \mathrm{L}(P<0.0001)$.
The TGs:HDL ratio, a surrogate marker of insulin resistance, decreased from $5.4 \pm 2$ to $2.5 \pm 0.6(P<0.0001)$.

\section{Effects on lipid profiles}

TTh resulted in gradual and consistent decrease in TC levels. The decrease was statistically significant as early as 12 months $(P<0.0001)$ and reached a plateau at 48 months $(P<0.01$ vs 36 months, thereafter nonsignificant). TC decreased from $7.8 \pm 0.9 \mathrm{mmol} / \mathrm{L}$ to $4.8 \pm 0.2 \mathrm{mmol} / \mathrm{L}$, LDL from $4.7 \pm 0.9 \mathrm{mmol} / \mathrm{L}$ to $3.0 \pm 0.7 \mathrm{mmol} / \mathrm{L}$, and TGs from $3.4 \pm 0.7 \mathrm{mmol} / \mathrm{L}$ to $2.1 \pm 0.1 \mathrm{mmol} / \mathrm{L}$. HDL increased from $1.6 \pm 0.5 \mathrm{mmol} / \mathrm{L}$ to $2 \pm 0.5 \mathrm{mmol} / \mathrm{L}$. The TC:HDL ratio declined from $5.5 \pm 2.0$ to $2.6 \pm 0.7$. Non-HDL cholesterol decreased from $241 \pm 30 \mathrm{mg} / \mathrm{dL}$ to $108 \pm 21 \mathrm{mg} / \mathrm{dL}$ ( $P<0.0001$ for all).

\section{Effects on SBP and DBP}

TTh produced marked and sustained gradual decrease in SBP from $164 \pm 14 \mathrm{mmHg}$ to $133 \pm 9 \mathrm{mmHg}$ representing a reduction of $33 \pm 1 \mathrm{mmHg}(P<0.0001$; Figure $3 \mathrm{~A})$. The decrease was significant and gradual over the first 6 years and remained low over the entire course of the 8 years of treatment. Similar results were recorded with the DBP, which decreased from $99 \pm 11 \mathrm{mmHg}$ to $77 \pm 5 \mathrm{mmHg}$ representing a reduction of $24 \pm 1 \mathrm{mmHg}(P<0.0001$; Figure 3B). Again, a marked decrease was noted over the first 6 years of treatment and then remained low over the entire 8 years of treatment.

\section{Effects on pulse pressure}

As shown in Figure 4, long-term TTh in hypogonadal patients with a history of CVD resulted in marked and significant reduction in pulse pressure from $65 \pm 6$ to $57 \pm 8$. The reduction in pulse pressure was gradual and significant over the course of treatment versus baseline as well as compared to the previous year for the first 2 years, with a mean change in pulse pressure of $9 \pm 1$ at the end of the follow-up period.

\section{Effects on heart rate and inflammation}

Heart rate (bpm) decreased from $79 \pm 4$ to $73 \pm 2$. C-reactive protein $(\mathrm{mg} / \mathrm{dL})$ declined from $3.7 \pm 4.5$ to $0.2 \pm 0.3(P<0.0001)$.

\section{Effects on liver enzymes}

Both aspartate aminotransferase and alanine aminotransferase decreased significantly.

\section{Effects on quality of life}

Questionnaires for general quality of life (AMS), voiding function (IPSS), and erectile function (IIEF-EF) improved 
significantly. Table 2 summarizes the findings of this study with regard to the changes in metabolic parameters and quality of life in men with history of CVD.

\section{Safety and compliance}

No patient had a major adverse CV event. No patient had a urological event (prostate cancer or voiding dysfunction). No patient missed a single injection. No patient dropped out.

\section{Discussion}

In this observational registry study, we followed up 77 men with hypogonadism and a history of CVD on continuous TTh for up to 8 years. Here, we show that in this subset of patients, TTh was associated with reduced body weight, WC, and BMI. The gradual and marked decrease in body weight and WC are of importance since metabolic syndrome (MetS) and obesity are recognized as risk factors for CVD and reduction in weight of this magnitude is meaningful for reducing CVD
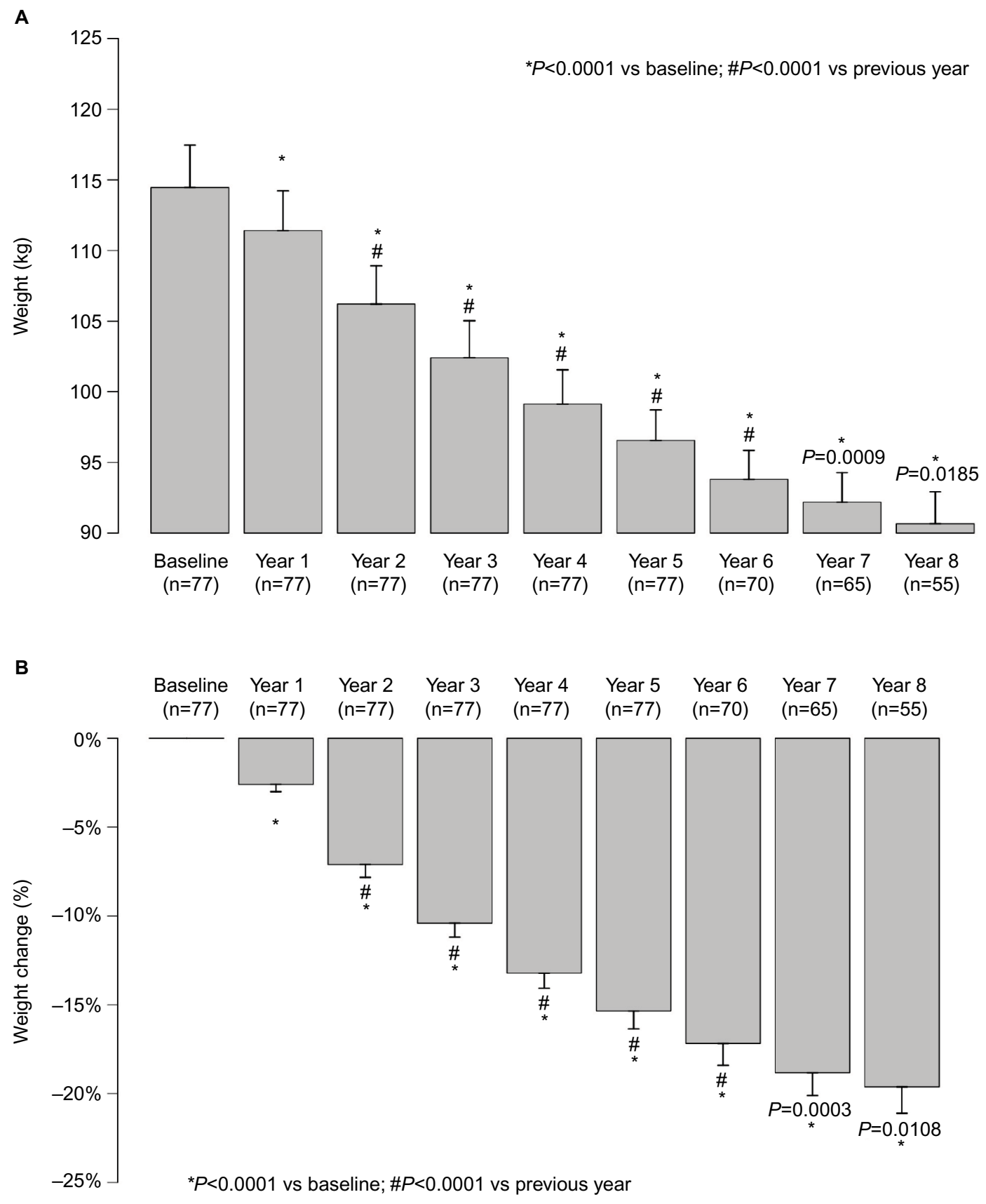

Figure I (Continued) 
C

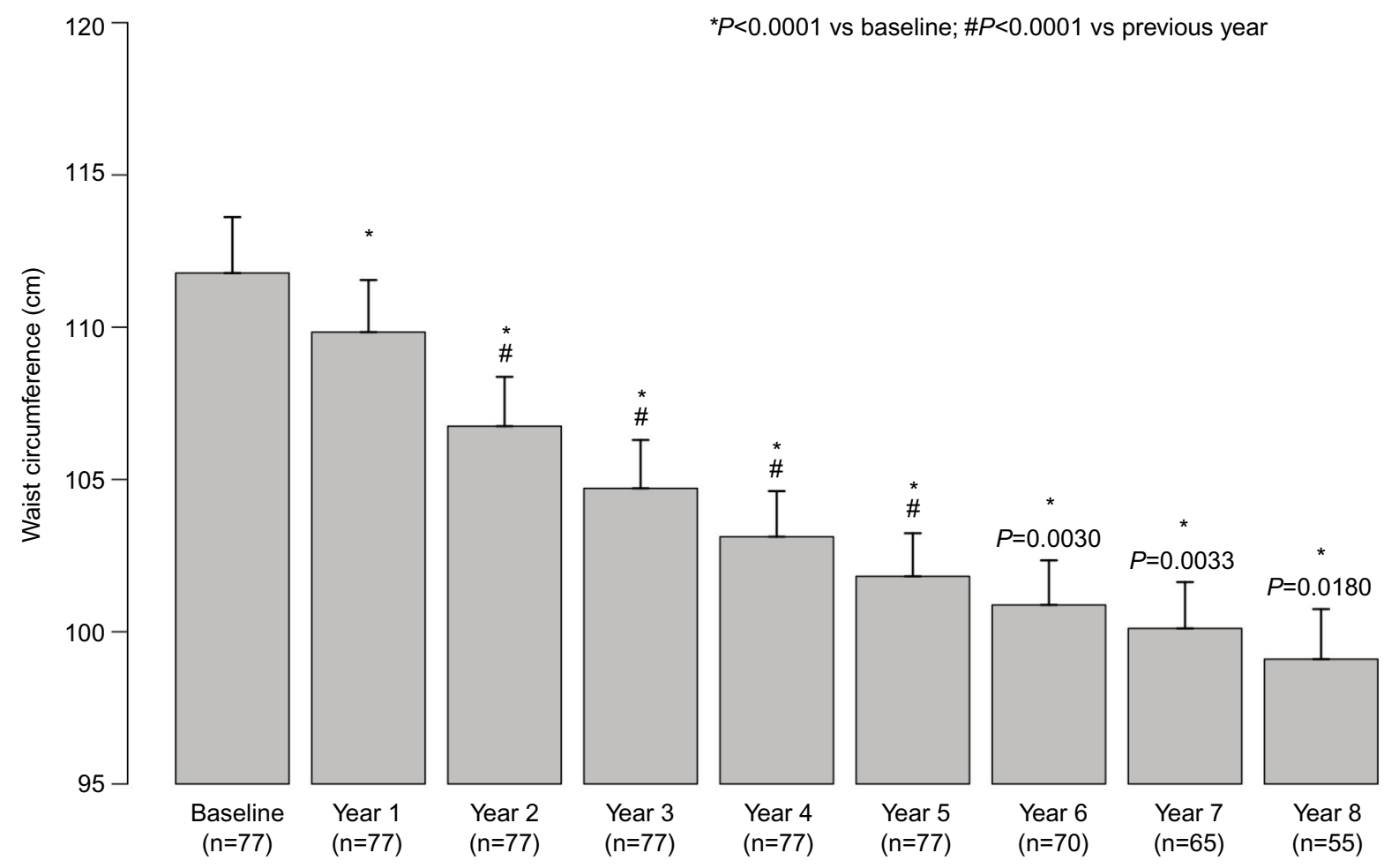

D

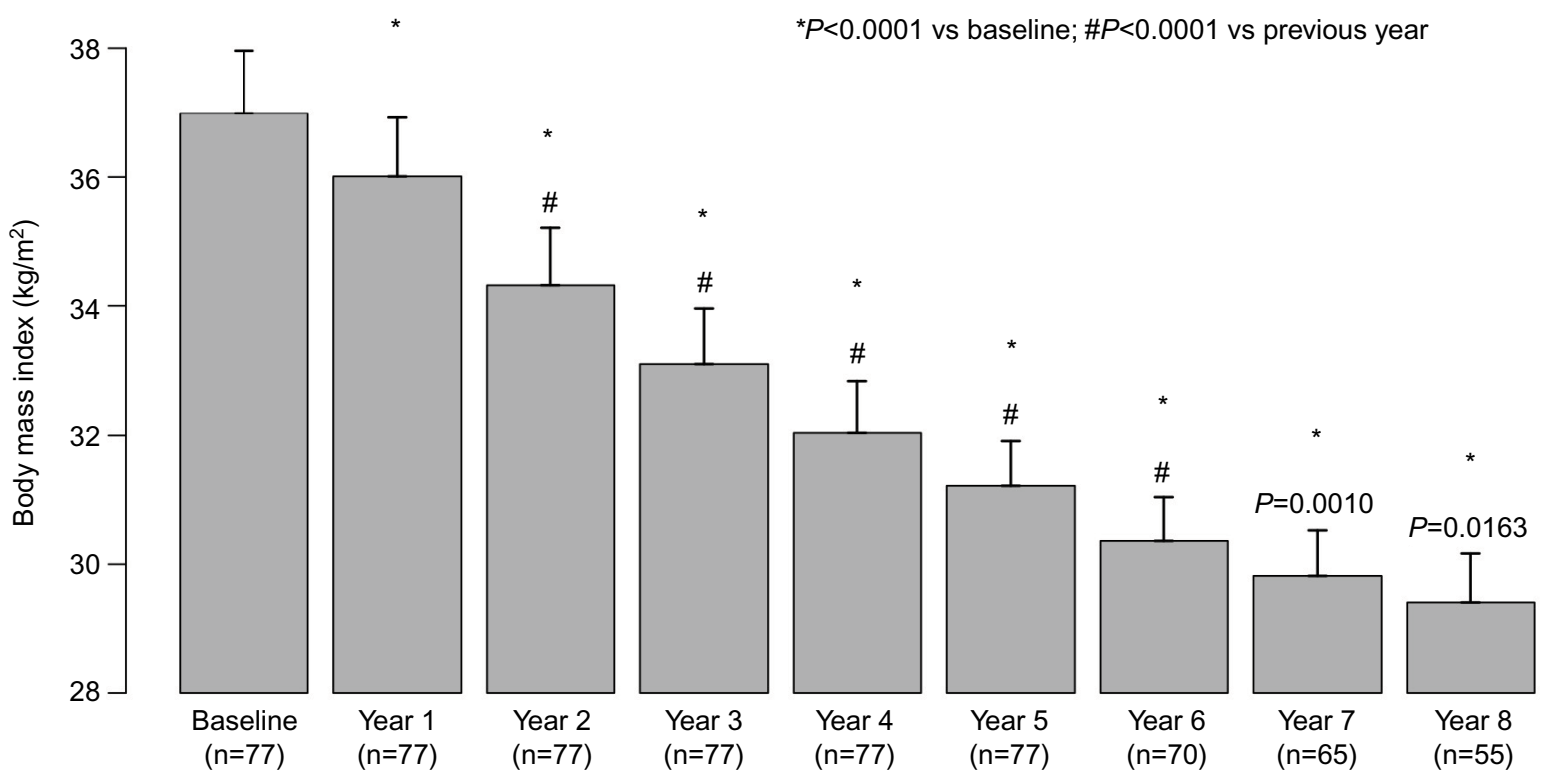

Figure I Anthropometric parameters in hypogonadal men with a history of cardiovascular disease receiving long-term testosterone therapy.

Notes: (A) Body weight (kg), (B) weight loss (\%), (C) waist circumference (cm), and (D) BMI $\left(\mathrm{kg} / \mathrm{m}^{2}\right)$. Data are shown as mean \pm SE.

Abbreviations: BMI, body mass index; SE, standard error. 


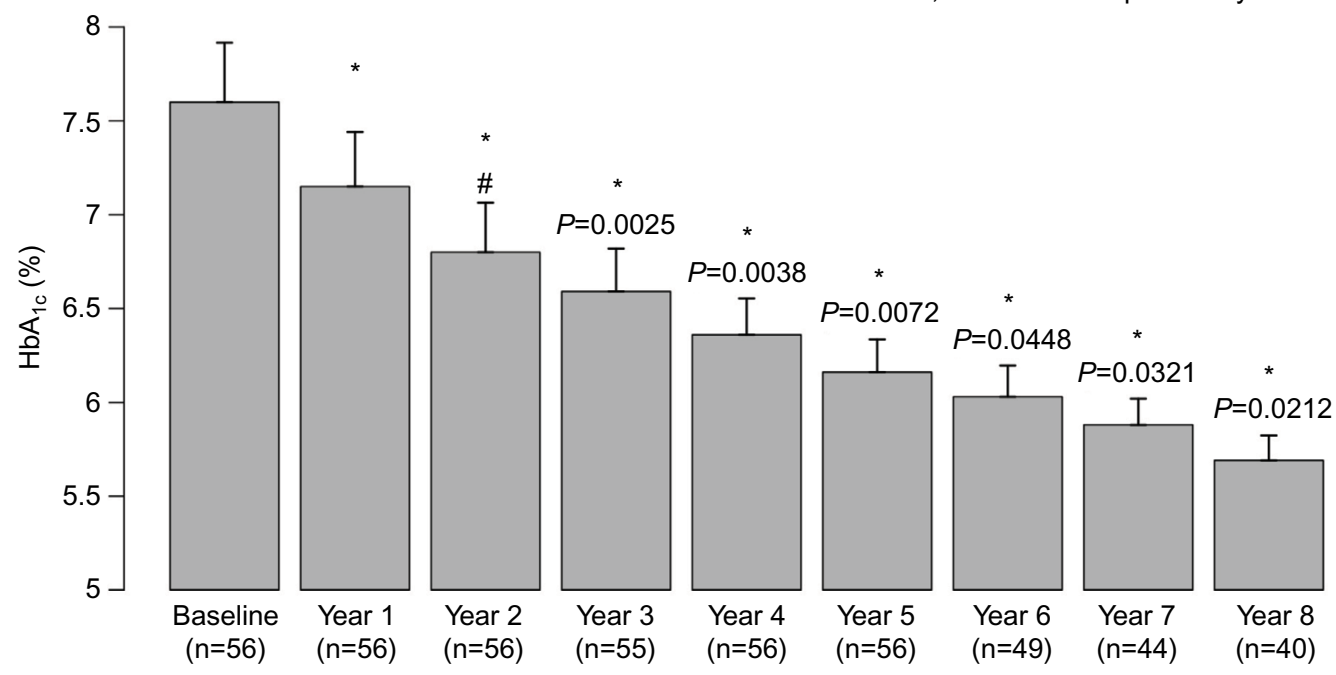

Figure $2 \mathrm{HbA}_{\mathrm{Ic}}(\%)$ in hypogonadal men with a history of cardiovascular disease receiving long-term testosterone therapy. Note: Data are shown as mean \pm SE.

Abbreviations: $\mathrm{HbA}_{\mathrm{lc}}$, glycated hemoglobin; $\mathrm{SE}$, standard error.

risk. It is not surprising to observe the gradual, progressive, and sustained WL over the course of 8 years of treatment, since TTh was shown to reduce fat mass and increase lean body mass in men with hypogonadism. ${ }^{1}$ However, what was unexpected is that these patients with a diagnosis of a lifethreatening disease had not been successful in managing their weight via other strategies. Their baseline BMI was $37 \mathrm{~kg} / \mathrm{m}^{2}$, and only one patient was in the normal weight category at baseline, five patients were overweight, and 71 (92\%) obese. More importantly, after 8 years of continuous TTh, we did not observe any increase in the classical CVD risk markers in this subset of patients,suggesting that this treatment does not increase the risk of CVD. The WL was associated with marked reductions in WC, suggesting that TTh ameliorates MetS components and may contribute to reduction in visceral fat, as described previously. ${ }^{20,21}$

We and others have reported that TTh produces positive effects on blood pressure, glucose levels, insulin sensitivity, $\mathrm{HbA}_{1 \mathrm{c}}$ levels, and MetS components. ${ }^{19-27}$ Diabetes is a major risk factor for CVD, and the majority of patients in this study were diabetics receiving standard treatment but with limited success according to their baseline $\mathrm{HbA}_{1 \mathrm{c}}$ levels of $7.6 \%$. Our findings corroborate previous reports that TTh ameliorates hyperglycemia and insulin resistance, which are sustained for a period of 8 years. This is of critical importance, because diabetes is a chronic, progressive disease, and TTh seems to successfully control it.

In this study, we also report on a remarkable decrease in the levels of TC, LDL, and TGs with notable increase in
HDL levels. We must note that despite most of the patients being treated with statins to control their dyslipidemia, most patients exhibited high levels of TC, LDL, and TGs at baseline. Our findings are consistent with data from other studies, which reported that long-term TTh in men with TD is associated with reduced levels of TC, LDL, and TGs coupled with beneficial increase in HDL. ${ }^{20-22,25-27}$ Such reductions in LDL and TGs and increased HDL have important implications in reducing CVD risk. ${ }^{20-22}$ Furthermore, we noted a lower TC:HDL ratio. Since TC:HDL ratio is thought to predict the risk of CVD, in particular, ischemic heart disease, such reduction suggests improvements in the overall lipid profile and potential reduction in CVD risk. It should be emphasized that findings from studies on ADT in patients with advanced prostate cancer consistently reported an increase in TC, TGs, and LDL, suggesting that ADT (ie, intentionally induced hypogonadism) produces undesirable lipid profile and increases the risk of CVD. ${ }^{2,3}$ Thus, we believe that TTh confers favorable improvement in cardiometabolic function and reduces the risk of CVD.

It has been suggested that $\mathrm{T}$ modulates arterial blood pressure through various mechanisms, and TD may contribute to hypertension. ${ }^{28}$ Interestingly, men treated with ADT for prostate cancer showed markedly increased arterial stiffness. ${ }^{29}$ Svartberg et al ${ }^{28}$ reported that SBP was inversely associated with $\mathrm{T}$ levels, suggesting that hypogonadism contributes to higher blood pressure and TTh may reduce blood pressure. ${ }^{20,21,28}$ In this study, we report a significant and gradual decrease in blood pressure in response to TTh, which 
A

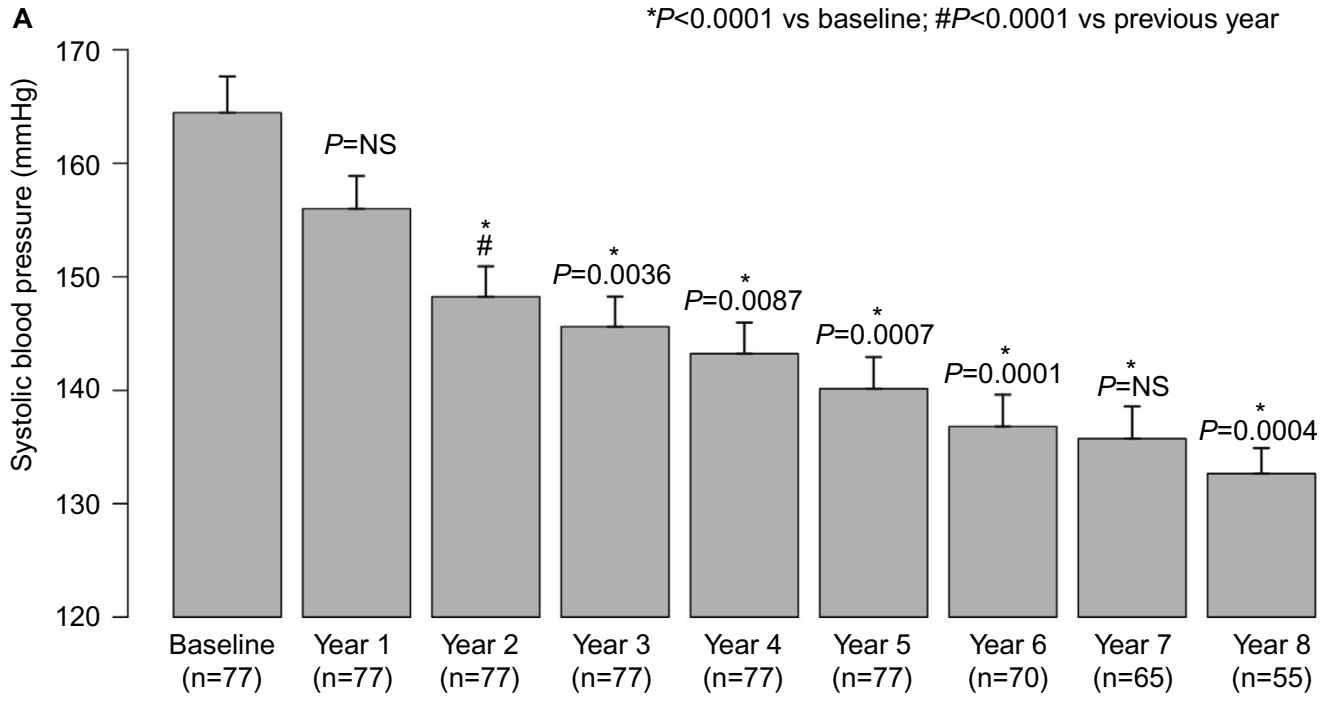

B

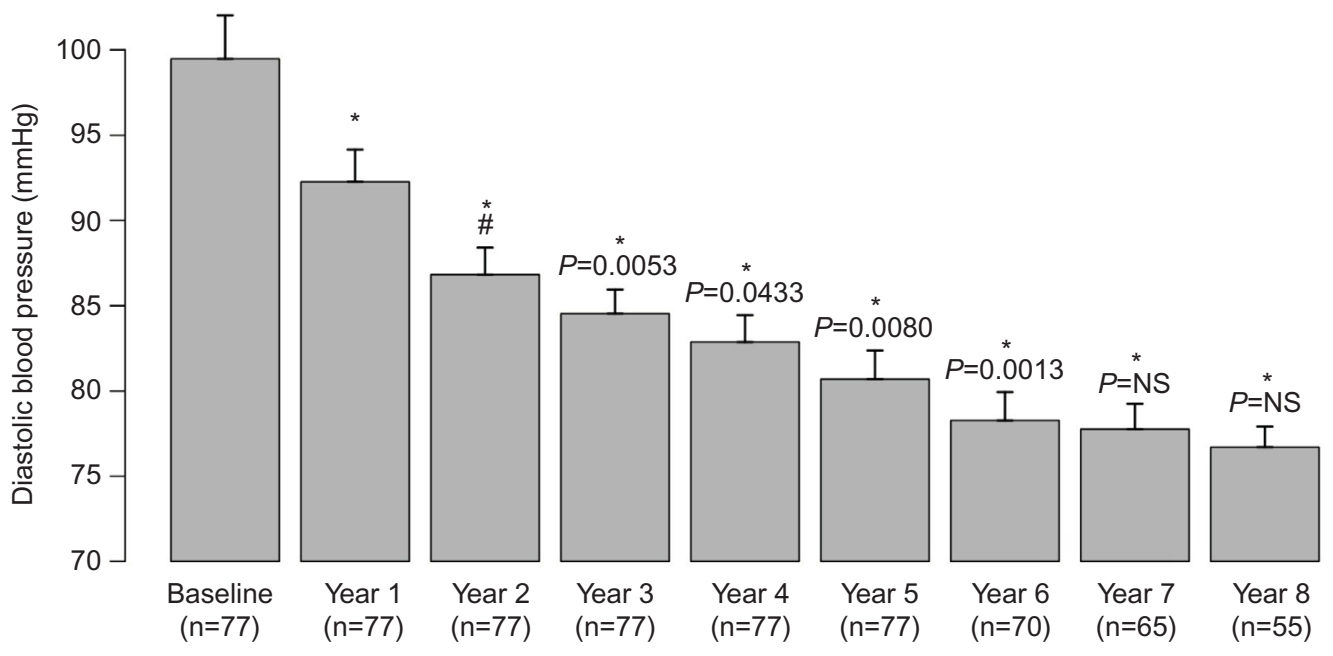

Figure 3 Blood pressure $(\mathrm{mmHg})$ in hypogonadal men with a history of cardiovascular disease receiving long-term testosterone therapy. Notes: (A) Systolic blood pressure and (B) diastolic blood pressure. Data are shown as mean $\pm \mathrm{SE}$.

Abbreviations: SE, standard error; NS, nonsignificant.

remained low over the entire course of the 8 years of TTh. We should emphasize that patients in this study were on antihypertensive drugs to control their blood pressure, yet they exhibited elevated blood pressure at baseline prior to TTh. Indeed, it has been suggested that TD may be a risk factor for hypertension, and TTh may ameliorate this parameter. ${ }^{19}$ As shown in Figure 3, TTh had a profound effect on blood pressure in this subset of patients with prior history of CVD.

The fact that the majority of patients were on concomitant medications (antihypertensives, lipid-lowering drugs, and antidiabetic medications) with limited success raises the question of medication adherence, which is known to be low in chronic diseases. Whether the effects of TTh are attributed solely to the physiological activity of $\mathrm{T}$ or augmentation of the medications for hypertension, diabetes, and dyslipidemia by administration of testosterone remains unknown. Injections of TU are invariably administered in the doctor's office so that a $100 \%$ adherence to TTh is guaranteed.

Our finding that pulse pressure, a surrogate marker for arterial stiffness, was significantly reduced is supported by data from a recent placebo-controlled study in which reduction in arterial stiffness was reported, following TTh. TTh has been shown to decrease arterial stiffness and respiratory quotient compared with placebo. TTh in men with 


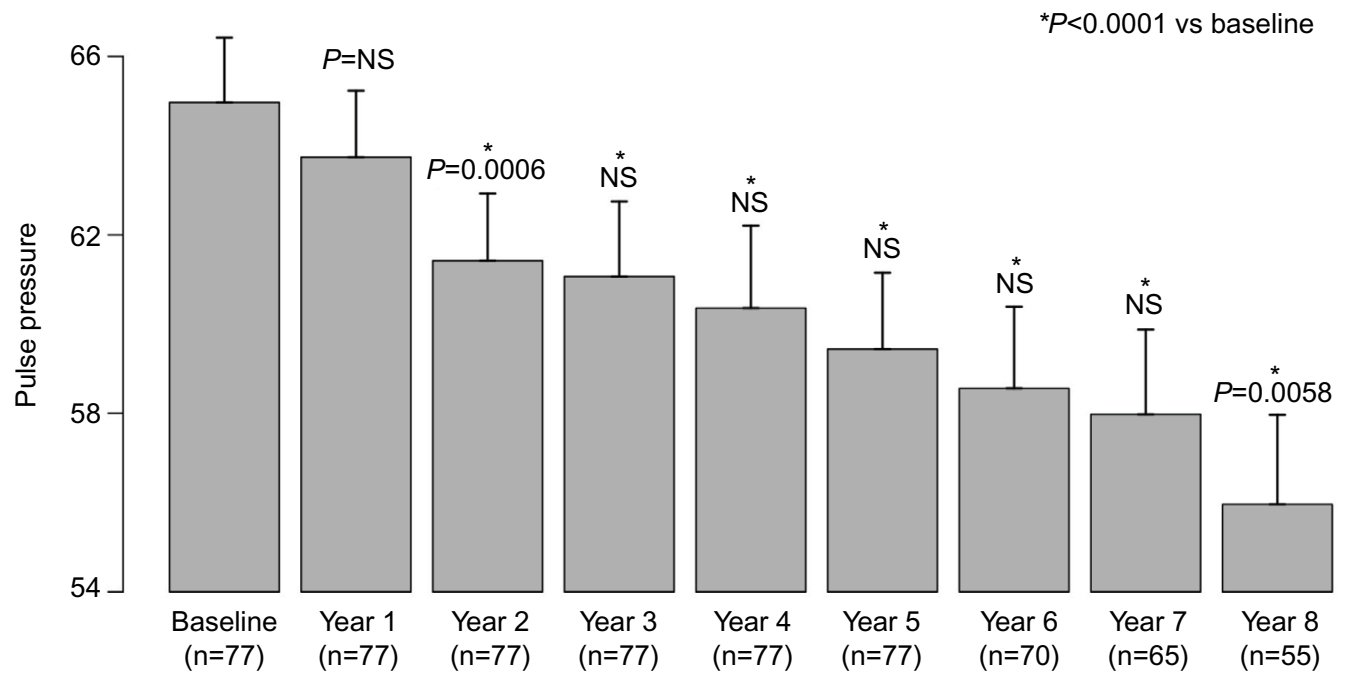

Figure 4 Pulse pressure in hypogonadal men with a history of cardiovascular disease receiving long-term testosterone therapy. Notes: Data are shown as mean $\pm \mathrm{SE}$

Abbreviations: SE, standard error; NS, nonsignificant.

hypogonadism reduced CVD risk factors with concomitant improvement in insulin sensitivity and glycemic control, even in studies of short duration. ${ }^{27}$ It should be noted that pulse pressure is considered a marker of vascular stiffness, and any reduction in this parameter is considered favorable for reducing CVD risk. ${ }^{30}$

Although epidemiological studies have suggested that reduced $\mathrm{T}$ levels are associated with greater CVD risk, ${ }^{31}$ the use of TTh to treat hypogonadism remains controversial. In light of the fact that a marked decrease in visceral fat mass, increased lean body mass, and reduced circulating inflammatory cytokines, concomitant with improvement in endothelial cell function, have been reported, ${ }^{24}$ it would be expected that TTh may reduce the risk of CVD. Since T regulates a host of physiological and metabolic functions in liver, adipose tissue, muscles, coronary arteries, and the heart, it is not surprising that TTh reduces the risk of CVD.

Mortality in men with TD was reduced subsequent to $\mathrm{TTh}^{32,33}$ Shores et al ${ }^{32}$ demonstrated that mortality in T-treated men was $10.3 \%$ compared with $20.7 \%$ in untreated hypogonadal men $(P<0.0001)$. Muraleedharan et al ${ }^{33}$ demonstrated, in hypogonadal men with type 2 diabetes mellitus, reduced mortality of $8.4 \%$ in men receiving TTh compared with $19.2 \%$ in untreated men. These findings are consistent with several studies summarized by Morgentaler et al. ${ }^{1} \mathrm{CV}$ benefits of TTh have been shown in interventional studies, including benefits in men with congestive heart failure, cardiac ischemia/angina, including a reduction in carotid intima-media thickness. ${ }^{1}$ Most studies identified an inverse association between serum $T$ concentration and all-cause or CV mortality.
Recently, Corona et $\mathrm{al}^{34}$ analyzed a large number of published studies for the benefits and risks of TTh and concluded that there was no evidence of increased CV risk with TTh but protective effects in men with metabolic disorders and suggested that TTh has benefits on cardiometabolic function. The well-recognized benefits of TTh in men with hypogonadism are the improvement in sexual desire and erectile function, ${ }^{34,35}$ increased energy, mood, and vitality, ${ }^{35-39}$ increased lean body mass, ${ }^{37,38}$ reduction in total body fat mass, ${ }^{37,38}$ and reduction in WC. . $^{20,21,25}$

It must be emphasized that several recent studies ${ }^{13-18}$ showed reduced incidence of MI, stroke and mortality in men treated with $\mathrm{T}$, achieving physiological $\mathrm{T}$ levels. The study by Sharma et a ${ }^{15}$ clearly showed the deficit of other studies in which incomplete restoration of physiological levels of $T$ was not accounted for, and when such information was not taken into consideration, the CVD risks reported cannot be taken seriously since they were not substantiated by evidence. The prospective controlled study by Morgunov et $\mathrm{a} \mathrm{l}^{39}$ showed that stroke patients treated with TU injections for 2 years starting 1 week after stroke occurrence had a significantly reduced incidence of recurrent stroke of $7.1 \%$ in the testosterone group compared to $16.6 \%$ in the untreated control group. ${ }^{39}$

It has been fiercely argued that most of the data presented in the aforementioned studies represent retrospective observational analyses or registry studies. We recognize that randomized controlled clinical trials are considered to be the gold standard for assessing the efficacy and safety of a given therapy. However, the costs associated with such trials recruiting 6,000 to 8,000 men with hypogonadism and treatment and follow-up for 5-10 years are astronomical, and no 
Table 2 Changes following testosterone therapy in anthropometric, metabolic, and quality of life parameters in hypogonadal men with a history of cardiovascular diseases

\begin{tabular}{|c|c|c|c|c|c|c|c|}
\hline & \multicolumn{7}{|c|}{ All CVD patients $(n=77)$} \\
\hline & Baseline \pm SD & Minimum & Maximum & 8 years \pm SD & Minimum & Maximum & Change $\pm \mathrm{SE}$ \\
\hline \multicolumn{8}{|l|}{ Anthropometry } \\
\hline Weight (kg) & $114 \pm 13$ & 72 & 139 & $91 \pm 9$ & 74 & 110 & $-24 \pm 1 *$ \\
\hline $\mathrm{BMI}\left(\mathrm{kg} / \mathrm{m}^{2}\right)$ & $37 \pm 4$ & 25 & 46 & $29 \pm 3$ & 25 & 35 & $-8 \pm 0 *$ \\
\hline Weight change (\%) & 0 & 0 & 0 & $-19.6 \pm 5.7$ & 3.1 & -29 & $-20.2 \pm 0.5^{*}$ \\
\hline Waist circumference $(\mathrm{cm})$ & $112 \pm 8$ & 88 & 129 & $99 \pm 6$ & 84 & 114 & $-13 \pm 0.3^{*}$ \\
\hline Waist:height ratio & $0.64 \pm 0.05$ & 0.51 & 0.73 & $0.56 \pm 0.04$ & 0.49 & 0.64 & $-0.07 \pm 0 *$ \\
\hline \multicolumn{8}{|l|}{ Testosterone } \\
\hline Testosterone (nmol/L) & $9.8 \pm 1.6$ & 4.8 & 11.8 & $16.8 \pm 1.9$ & 14.7 & 23.8 & $6.9 \pm 0.3^{*}$ \\
\hline \multicolumn{8}{|l|}{ Prostate parameters } \\
\hline Prostate volume $(\mathrm{mL})$ & $34 \pm 10$ & 16 & 56 & $36 \pm 10$ & 17 & 57 & $2.5 \pm 0.2 *$ \\
\hline PSA (ng/mL) & $2.0 \pm 1.0$ & 0.1 & 3.9 & $2.2 \pm 0.8$ & 0.8 & 3.5 & $0.2 \pm 0.0^{*}$ \\
\hline IPSS & $9 \pm 4$ & I & 19 & $3 \pm 2$ & I & 10 & $-7 \pm 0.3^{*}$ \\
\hline \multicolumn{8}{|l|}{ Erectile function } \\
\hline IIEF-EF & $20 \pm 6$ & 3 & 27 & $25 \pm 5$ & 12 & 29 & $6 \pm 0.4^{*}$ \\
\hline \multicolumn{8}{|l|}{ Quality of life } \\
\hline AMS & $57 \pm 9$ & 36 & 73 & $19 \pm 4$ & 17 & 30 & $-39 \pm 1 *$ \\
\hline \multicolumn{8}{|l|}{ Glycemic control } \\
\hline Fasting glucose (mmol/L) & $6.0 \pm 1.2$ & 3.7 & 12.7 & $5.2 \pm 0.4$ & 4.0 & 6.6 & $-0.9 \pm 0.1^{*}$ \\
\hline $\mathrm{HbA}_{\mathrm{Ic}}(\%)$ & $7.6 \pm 1.2$ & 5.1 & 9.4 & $5.7 \pm 0.4$ & 5.0 & 6.6 & $-2.0 \pm 0.1^{*}$ \\
\hline Triglycerides:HDL ratio & $5.4 \pm 2$ & 2.0 & 11.3 & $2.5 \pm 0.6$ & 1.6 & 4.0 & $-3.1 \pm 0.1 *$ \\
\hline \multicolumn{8}{|l|}{ Lipids } \\
\hline Total cholesterol $(\mathrm{mmol} / \mathrm{L})$ & $7.8 \pm 0.9$ & 5.7 & 10.1 & $4.8 \pm 0.2$ & 4.3 & 5.3 & $-3 \pm 0.1 *$ \\
\hline $\mathrm{HDL}(\mathrm{mmol} / \mathrm{L})$ & $1.6 \pm 0.5$ & 0.7 & 2.3 & $2 \pm 0.5$ & 1.2 & 3.1 & $0.6 \pm 0.0 *$ \\
\hline LDL (mmol/L) & $4.7 \pm 0.9$ & 2.0 & 7.2 & $3.0 \pm 0.7$ & I.I & 4.1 & $-1.6 \pm 0.1 *$ \\
\hline Triglycerides (mmol/L) & $3.4 \pm 0.7$ & 1.4 & 5 & $2.1 \pm 0.1$ & 1.8 & 2.4 & $-1.3 \pm 0.1 *$ \\
\hline Total cholesterol:HDL ratio & $5.5 \pm 2$ & 3.5 & 12.9 & $2.6 \pm 0.7$ & 1.6 & 4.1 & $-3.2 \pm 0.1^{*}$ \\
\hline Non-HDL cholesterol $(\mathrm{mg} / \mathrm{dL})$ & $24 I \pm 30$ & 163 & 332 & $|08 \pm 2|$ & 68 & 152 & $-136 \pm 3 *$ \\
\hline \multicolumn{8}{|l|}{ Erythropoiesis/blood count } \\
\hline Hemoglobin $(g / d L)$ & $14.4 \pm 0.7$ & 12.1 & 15.5 & $15.0 \pm 0.5$ & 13.8 & 15.8 & $0.7 \pm 0.1^{*}$ \\
\hline Hematocrit (\%) & $43.2 \pm 3.1$ & 33 & 50 & $48.1 \pm 1.6$ & 43.5 & 51 & $5.0 \pm 0.3^{*}$ \\
\hline Leukocytes $\left(10^{9} / \mathrm{L}\right)$ & $7.1 \pm 2.2$ & 4.3 & 19.8 & $6.5 \pm 0.5$ & 5.5 & 7.5 & $-0.6 \pm 0.2^{\#}$ \\
\hline \multicolumn{8}{|l|}{ Liver transaminases } \\
\hline AST (U/L) & $40.7 \pm 14.7$ & 19 & 87 & $17.4 \pm 4.2$ & 12.3 & 32.5 & $-23.8 \pm 1.2 *$ \\
\hline $\mathrm{ALT}(\mathrm{U} / \mathrm{L})$ & $41.5 \pm 17.1$ & 19 & 100 & $17.4 \pm 4.8$ & 9.8 & 30 & $-24.9 \pm 1.5^{*}$ \\
\hline AST:ALT ratio & $1.0 \pm 0.2$ & 0.7 & 1.4 & $1.0 \pm 0.1$ & 0.8 & 1.3 & $0.0 \pm 0.0$ \\
\hline \multicolumn{8}{|l|}{ Inflammation } \\
\hline CRP (mg/dL) & $3.7 \pm 4.5$ & 0.1 & 24.7 & $0.2 \pm 0.3$ & 0.1 & 1.3 & $-3.6 \pm 0.3 *$ \\
\hline \multicolumn{8}{|l|}{ Blood pressure } \\
\hline Systolic (mmHg) & $164 \pm 14$ & 125 & 189 & $133 \pm 9$ & 117 & 152 & $-33 \pm I^{*}$ \\
\hline Diastolic (mmHg) & $99 \pm 11$ & 70 & 119 & $77 \pm 5$ & 70 & 89 & $-24 \pm I^{*}$ \\
\hline Pulse pressure & $65 \pm 6$ & 49 & 82 & $57 \pm 8$ & 34 & 69 & $-9 \pm I^{*}$ \\
\hline Heart rate (bpm) & $79 \pm 4$ & 72 & 88 & $73 \pm 2$ & 68 & 81 & $-6 \pm 0 *$ \\
\hline
\end{tabular}

Notes: ${ }^{*} P<0.0001$ vs baseline. ${ }^{\#} P<0.01$.

Abbreviations: CVD, cardiovascular disease; SD, standard deviation; SE, standard error; BMI, body mass index; PSA, prostate-specific antigen; IPSS, International Prostate Symptom Score; IIEF-EF, International Index of Erectile Function, Erectile Function domain; AMS, Aging Males' Symptoms scale; HbA density lipoprotein; LDL, low-density lipoprotein; AST, aspartate aminotransferase; ALT, alanine aminotransferase; CRP, C-reactive protein.

governmental agency or pharmaceutical industry would wish to incur such costs. Evidence-based medicine should be based on data reported from randomized, placebo-controlled trials as well as from prospective or retrospective observational studies, registries, case control studies, and meta-analyses to glean all the critical information. Therefore, it is imperative that we utilize all available data irrespective of the nature of the study to extract relevant information on TTh to advance our knowledge of the benefits and risks of TTh.

It has been strongly suggested that observational and registry studies are a useful source of real-life data that provide valuable clinical information that augments and complements 
data from other types of studies, including randomized controlled trials. Observational studies provide relevant information on the benefit and risks to patients in routine clinical practice. ${ }^{40}$ Of course, we must keep in mind that similar to all other studies, observational studies have their own unique limitations, which should be carefully considered in the assessment of risk and treatment benefit. ${ }^{40}$ The scientific and clinical community appreciates the fact that data from observational studies may not provide complete or adequate information to separate the effects of a new treatment from other factors. Nevertheless, observational studies are considered representative of the daily routine clinical practices that are encountered in the general population and provide critical information on the long-term safety and effectiveness in clinical practice, especially relevant information regarding adherence and health outcomes in the general population. ${ }^{40}$

\section{Study limitations}

The present study was not designed or powered to address the effects of TTh in men with existing CVD. There was no adjudication of previous $\mathrm{CV}$ events that were reported by the patients as part of their anamnesis. Since patients were treated for their underlying diseases by other specialists than the urologists performing TTh, there was no precise monitoring of concomitant medications so that changes in medication cannot be excluded. There was no control group.

\section{Conclusion}

Long-term TTh in men with hypogonadism and a history of CVD appears to be an effective approach to achieve sustained improvements in anthropometric parameters and cardiometabolic function, with no reported increases in CVD events. The fact that none of these high-risk patients had another $\mathrm{CV}$ event may suggest that TTh can have beneficial effects in men with a history of CVD, provided comprehensive secondary prevention therapy is already in place.

\section{Disclosure}

A Haider and A Yassin have received partial compensation for data entry and travel grants from Bayer Pharma. G Doros has received payment for statistical analyses from Bayer Pharma. F Saad is a full-time employee of Bayer Pharma. KS Haider and GMC Rosano have nothing to disclose.

\section{References}

1. Morgentaler A, Miner MM, Caliber M, Guay AT, Khera M, Traish AM. Testosterone therapy and cardiovascular risk: advances and controversies. Mayo Clin Proc. 2015;90(2):224-251.
2. Traish AM. Adverse health effects of testosterone deficiency (TD) in men. Steroids. 2014;88:106-116.

3. Jespersen CG, Nørgaard M, Borre M. Androgen-deprivation therapy in treatment of prostate cancer and risk of myocardial infarction and stroke: a nationwide Danish population-based cohort study. Eur Urol. 2014;65(4):704-709.

4. Rosano GM, Sheiban I, Massaro R, et al. Low testosterone levels are associated with coronary artery disease in male patients with angina. Int J Impot Res. 2007;19(2):176-182.

5. Srinath R, Hill Golden S, Carson KA, Dobs A. Endogenous testosterone and its relationship to preclinical and clinical measures of cardiovascular disease in the atherosclerosis risk in communities study. $J$ Clin Endocrinol Metab. 2015;100(4):1602-1608.

6. Laaksonen DE, Niskanen L, Punnonen K, et al. Testosterone and sex hormone-binding globulin predict the metabolic syndrome and diabetes in middle-aged men. Diabetes Care. 2004;27(5):1036-1041.

7. Antonio L, Wu FC, O'Neill TW, et al; EMAS Study Group. Associations between sex steroids and the development of metabolic syndrome: a longitudinal study in European men. J Clin Endocrinol Metab. 2015;100(4):1396-1404.

8. Narayanan K, Havmoeller R, Reinier K, et al. Sex hormone levels in patients with sudden cardiac arrest. Heart Rhythm. 2014;11(12): 2267-2272.

9. Basaria S, Coviello AD, Travison TG, et al. Adverse events associated with testosterone administration. N Engl J Med. 2010;363(2):109-122.

10. Xu L, Freeman G, Cowling BJ, Schooling CM. Testosterone therapy and cardiovascular events among men: a systematic review and meta-analysis of placebo-controlled randomized trials. BMC Med. 2013;18(11):108.

11. Vigen R, O’Donnell CI, Barón AE, et al. Association of testosterone therapy with mortality, myocardial infarction, and stroke in men with low testosterone levels. JAMA. 2013;310(17):1829-1836. Erratum in: JAMA. 2014;311(9):967.

12. Finkle WD, Greenland S, Ridgeway GK, et al. Increased risk of nonfatal myocardial infarction following testosterone therapy prescription in men. PLoS One. 2014;9(1):e85805.

13. Baillargeon J, Urban RJ, Kuo YF, et al. Risk of myocardial infarction in older men receiving testosterone therapy. Ann Pharmacother. 2014;48(9):1138-1144.

14. Baillargeon J, Urban RJ, Morgentaler A, et al. Risk of venous thromboembolism in men receiving testosterone therapy. Mayo Clin Proc. 2015;90(8):1038-1045.

15. Sharma R, Oni OA, Gupta K, et al. Normalization of testosterone level is associated with reduced incidence of myocardial infarction and mortality in men. Eur Heart J. 2015;36(40):2706-2715.

16. Tan RS, Cook KR, Reilly WG. Myocardial infarction and stroke risk in young healthy men treated with injectable testosterone. Int J Endocrinol. 2015;2015:970750.

17. Etminan M, Skeldon SC, Goldenberg SL, Carleton B, Brophy JM. Testosterone therapy and risk of myocardial infarction: a pharmacoepidemiologic study. Pharmacotherapy. 2015;35(1):72-78.

18. Anderson JL, May HT, Lappé DL, et al. Impact of testosterone replacement therapy on myocardial infarction, stroke, and death in men with low testosterone concentrations in an integrated healthcare system. $\mathrm{Am}$ J Cardiol. 2016;117(5):794-799.

19. Traish AM, Haider A, Doros G, Saad F. Long-term testosterone therapy in hypogonadal men ameliorates elements of the metabolic syndrome: an observational, long-term registry study. Int J Clin Pract. 2014;68(3):314-329.

20. Saad F, Haider A, Doros G, Traish A. Long-term treatment of hypogonadal men with testosterone produces substantial and sustained weight loss. Obesity (Silver Spring). 2013;21(10):1975-1981.

21. Saad F, Yassin A, Doros G, Haider A. Effects of long-term treatment with testosterone on weight and waist size in 411 hypogonadal men with obesity classes I-III: observational data from two registry studies. Int $J$ Obes. 2016;40(1):162-170. 
22. Pietri P, Vlachopoulos C, Ioakeimidis N, et al. 5B.06: association of plasma testosterone with central haemodynamics in hypertensive men. J Hypertens. 2015;33(suppl 1):e67.

23. Hackett G, Cole N, Bhartia M, et al; BLAST Study Group. Testosterone replacement therapy improves metabolic parameters in hypogonadal men with type 2 diabetes but not in men with coexisting depression: the BLAST study. $J$ Sex Med. 2014;11(3):840-856.

24. Jones TH, Arver S, Behre HM, et al. Testosterone replacement in hypogonadal men with type 2 diabetes and/or metabolic syndrome (the TIMES2 study). Diabetes Care. 2011;34(4):828-837.

25. Nedogoda SV, Barykina IN, Salasyuk AS, Smirnova VO, Khripaeva VJ. Effects of testosterone replacement therapy on cardio-metabolic, hormonal and anthropometric parameters in obese hypogonadal men with metabolic syndrome. Obesity. 2015;1(2):1-7.

26. Francomano D, Lenzi A, Aversa A. Effects of five-year treatment with testosterone undecanoate on metabolic and hormonal parameters in ageing men with metabolic syndrome. Int J Endocrinol. 2014;2014:527470.

27. Aversa A, Bruzziches R, Francomano D, et al. Effects of long-acting testosterone undecanoate on bone mineral density in middle-aged men with late-onset hypogonadism and metabolic syndrome: results from a 36 months controlled study. Aging Male. 2012;15(2):96-102.

28. Svartberg J, von Mühlen D, Schirmer H, Barrett-Connor E, Sundfjord J, Jorde R. Association of endogenous testosterone with blood pressure and left ventricular mass in men. Tromsø Study. Eur J Endocrinol. 2004;150(1):65-71.

29. Dockery F, Bulpitt CJ, Agarwal S, Donaldson M, Rajkumar C. Testosterone suppression in men with prostate cancer leads to an increase in arterial stiffness and hyperinsulinaemia. Clin Sci. 2003;104(2):195-201.

30. Vlachopoulos C, Ioakeimidis N, Miner M, et al. Testosterone deficiency: a determinant of aortic stiffness in men. Atherosclerosis. 2014;233(1):278-283.

31. Ohlsson C, Barrett-Connor E, Bhasin S, et al. High serum testosterone is associated with reduced risk of cardiovascular events in elderly men. The MrOS (Osteoporotic fractures in men) study in Sweden. J Am Coll Cardiol. 2011;58(16):1674-1682.
32. Shores MM, Smith NL, Forsberg CW, Anawalt BD, Matsumoto AM. Testosterone treatment and mortality in men with low testosterone levels. J Clin Endocrinol Metab. 2012;97(6):2050-2058.

33. Muraleedharan V, Marsh H, Kapoor D, Channer KS, Jones TH. Testosterone deficiency is associated with increased risk of mortality and testosterone replacement improves survival in men with type 2 diabetes. Eur J Endocrinol. 2013;169(6):725-733.

34. Corona G, Maseroli E, Rastrelli G, et al. Cardiovascular risk associated with testosterone-boosting medications: a systematic review and metaanalysis. Expert Opin Drug Saf. 2014;13(10):1327-1351.

35. Hackett G, Cole N, Bhartia M, Kennedy D, Raju J, Wilkinson P. Testosterone replacement therapy with long-acting testosterone undecanoate improves sexual function and quality of-life parameters vs. placebo in a population of men with type 2 diabetes. J Sex Med. 2013;10(6): $1612-1627$.

36. Tong SF, Ng CJ, Lee BC, et al. Effect of long-acting testosterone undecanoate treatment on quality of life in men with testosterone deficiency syndrome: a double blind randomized controlled trial. Asian J Androl. 2012;14(4):604-611.

37. Srinivas-Shankar U, Roberts SA, Connolly MJ, et al. Effects of testosterone on muscle strength, physical function, body composition, and quality of life in intermediate-frail and frail elderly men: a randomized, double-blind, placebo-controlled study. J Clin Endocrinol Metab. 2010;95(2):639-650.

38. Zitzmann M, Mattern A, Hanisch J, Gooren L, Jones H, Maggi M. IPASS: a Study on the tolerability and effectiveness of injectable testosterone undecanoate for the treatment of male hypogonadism in a worldwide sample of 1438 men. J Sex Med. 2013;10(2):579-588.

39. Morgunov L, Denisola I, Rohzkova T, Stakhovskaya LV, Skvortsova VI. Androgen deficit and its treatment in stroke male patients with type II diabetes. Zh Nevrol Psikhiatr Im S S Korsakova. 2011;8(2): 21-24.

40. Cohen AT, Goto S, Schreiber K, Torp-Pedersen C. Why do we need observational studies of everyday patients in the real-life setting? Eur Heart J Suppl. 2015;17(suppl D):D2-D8.
Vascular Health and Risk Management

\section{Publish your work in this journal}

Vascular Health and Risk Management is an international, peerreviewed journal of therapeutics and risk management, focusing on concise rapid reporting of clinical studies on the processes involved in the maintenance of vascular health; the monitoring, prevention and treatment of vascular disease and its sequelae; and the involvement of

\section{Dovepress}

metabolic disorders, particularly diabetes. This journal is indexed on PubMed Central and MedLine. The manuscript management system is completely online and includes a very quick and fair peer-review system, which is all easy to use. Visit http://www.dovepress.com/ testimonials.php to read real quotes from published authors. 